\title{
USO E OCUPAÇÃO DA TERRA EM ÁREAS DE PRESERVAÇÃO PERMANENTE NO MUNICÍPIO ALTA FLORESTA, MATO GROSSO
}

Charles Caioni ${ }^{1}$, Sandra Mara Alves da Silva Neves ${ }^{2,}$ Sheila Caioni ${ }^{3}$, Tiago de Lisboa Parente $^{3}$, Bruniely de Paula Rodrigues ${ }^{4}$

1 Pós-graduando em Ecologia e Conservação, Universidade do Estado de Mato Grosso, Nova Xavantina, Mato Grosso, (charlescaioni1@gmail.com)

2 Professor Adjunto ao departamento de Geografia da Unemat, Universidade do

Estado de Mato Grosso, Cáceres, Mato Grosso

3 Pós-graduando em Agronomia, Universidade Estadual Paulista (UNESP),

Faculdade de Engenharia, Ilha Solteira, São Paulo

4 Graduanda em Agronomia, Universidade do Estado de Mato Grosso, Cáceres, Mato Grosso

Recebido em: 08/04/2017 - Aprovado em: 10/06/2017 - Publicado em: 20/06/2017 DOI: 10.18677/EnciBio_2017A100

\section{RESUMO}

A supressão das áreas de matas ciliares decorrente das ações antrópicas vêm causando ao longo dos anos, fortes impactos na disponibilidade hídrica das microbacias. Em meio a este contexto encontra-se a microbacia Lago da Capivara, que em decorrência de posicionamento geográfico, torna-se estratégica para o futuro abastecimento urbano do município Alta Floresta, Mato Grosso. Nesta ótica, objetivou-se analisar os principais usos e ocupações da terra da microbacia Lago da Capivara, no município de Alta Floresta MT. Por meio do software ArcGis 9.3 realizou-se o procedimento de classificação de uso e ocupação da terra, na imagem SPOT 2.5 do ano de 2007, cedida pela Secretaria Municipal de Alta Floresta SECMA. As categorias utilizadas foram: Floresta Ombrófila Aberta, Influencia Urbana, Massa d'Água, Pastagem Plantada e Solo Exposto. Quantificou-se também a dimensão das Áreas de Preservação Permanente (APPs), de acordo com a lei de no 12.651/2012. Constatou-se que $41,61 \%$ das áreas da microbacia são ocupadas por pastagens, seguida de $25,41 \%$ por influência urbana. Contudo para as APPs observou-se que $52,66 \%$ encontram-se ocupadas por remanescentes florestais, seguido por $23,38 \%$ de monocultivos de forrageiras, $17,97 \%$ por influência urbana, $5,62 \%$ por massa d'agua e $0,37 \%$ por solo exposto. De modo geral identificou-se a necessidade de imediatas medidas de mitigação nas perdas da cobertura florestal dentro da microbacia Lago da Capivara.

PALAVRAS-CHAVE: mata ciliar, recurso hídrico, uso antrópico do solo

\section{USE AND OCCUPATION OF THE LAND IN AREAS OF PERMANENT PRESERVATION IN THE MUNICIPALITY OF ALTA FLORESTA, MATO GROSSO}

\footnotetext{
ABSTRACT

The suppression of riparian forest areas due to the anthropic actions has caused over the years, strong impacts on the water availability of the microcatchments. In the midst of this context is the Lago da Capivara lake, which due to its geographic positioning, becomes strategic for the future urban supply of the municipality of Alta ENCICLOPÉDIA BIOSFERA, Centro Científico Conhecer - Goiânia, v.14 n.25; p.1221 
Floresta, Mato Grosso. In this perspective, the objective was to analyze the main uses and occupations of the land of the Lago da Capivara microbasin present in the municipality of Alta Floresta MT. The ArcGIS 9.3 software was used to classify land use and occupation in the SPOT 2.5 image of the year 2007, provided by the Municipal Secretariat of Alta Floresta - SECMA. The categories used were: Open Ombrophylous Forest, Urban Influence, Water Mass, Planted Grassland and Exposed Soil. It was also quantified the size of the Areas of Permanent Preservation (APPs) according to the law of $n .12 .651 / 2012$. It was verified that $41.61 \%$ of the areas of the watershed are occupied by pastures, followed by $25.41 \%$ by urban influence. However, for the APPs, $52.66 \%$ were occupied by forest remnants, followed by $23.38 \%$ of forage monocultures, $17.97 \%$ by urban influence, $5.62 \%$ by water mass and $0.37 \%$ for exposed soil. In general, it was identified the need for immediate mitigation measures in forest cover losses within the Lago da Capivara microbasin.

KEYWORDS: water resource, riparian forest, anthropic use of soil

\section{INTRODUÇÃO}

As microbacias são importantes tanto para a manutenção da biodiversidade quanto para o desenvolvimento de diferentes atividades econômicas. De acordo com MARTIN (2000), entende-se como microbacia uma área entre um fundo de vale (rio, riacho, sanga e várzeas) e os espigões (divisores de água) que delimitam os pontos dos quais toda a água das chuvas escorre para esse fundo de vale.

Por receberem elevados volumes de água provenientes das chuvas, é indispensável a presença de matas ciliares nessas áreas. Conforme OLIVEIRA et al. (2013), as matas ciliares promovem proteção e aumento da capacidade de infiltração de água no solo, funcionando como uma espécie de esponja, evitando as enxurradas e regulando o ciclo hidrológico.

Apesar da importância da cobertura vegetal da floresta, nos últimos anos grande parte das Áreas de Preservação Permanente (APP) vem sofrendo fortes pressões antrópicas (LACORTE \& ALMEIDA, 2015), decorrente da substituição parcial ou integral das matas ciliares pelas mais distintas formas de uso antrópico da terra. Em muitas regiões, o avanço desordenado da atividade agrícola associado ao crescimento urbano vem provocando ainda maiores agravamentos nesse quadro. No estado de Mato Grosso, a conversão da cobertura vegetal nativa em áreas de pastagem e lavoura tem ocasionado o surgimento de processos erosivos nas encostas dos rios, e posteriormente o assoreamento de nascentes (SILVA \& SOUZA, 2012).

Neste sentido, o uso do sensoriamento remoto configura-se como uma importante ferramenta de análise dos principais usos do solo (LONGLEY et al., 2013), permitindo em curto espaço de tempo a obtenção de vastas redes de dados, os quais são gerados nos mapeamentos de uso e ocupação, sendo relevantes para amparar políticas de fiscalização e desenvolvimento regional em diferentes escalas (FREITAS, 2012).

Em meio a este cenário, encontra-se no perímetro urbano do município de Alta Floresta - MT a microbacia Lago da Capivara, onde o avanço do uso antrópico do solo sobre as áreas de APP tem posto em risco a perpetuação da disponibilidade hídrica à população. Nesta ótica, objetivou-se analisar os principais usos e ocupações da terra da microbacia Lago da Capivara, no município de Alta Floresta. 


\section{MATERIAL E MÉTODOS}

O estudo foi realizado na microbacia Lago da Capivara, localizada no município de Alta Floresta - Mato Grosso (Figura 1). A população municipal totaliza 50.082 habitantes, sendo a maioria residente da zona urbana (IBGE, 2016). O Índice de Desenvolvimento Humano (IDH-M) do município é de 0,714, abaixo do IDH do estado que é de 0,725 e do Brasil que é de 0,730 (PNUD, 2013). As principais bases econômicas são a pecuária extensiva e a agricultura (CAIONI et al., 2014b).

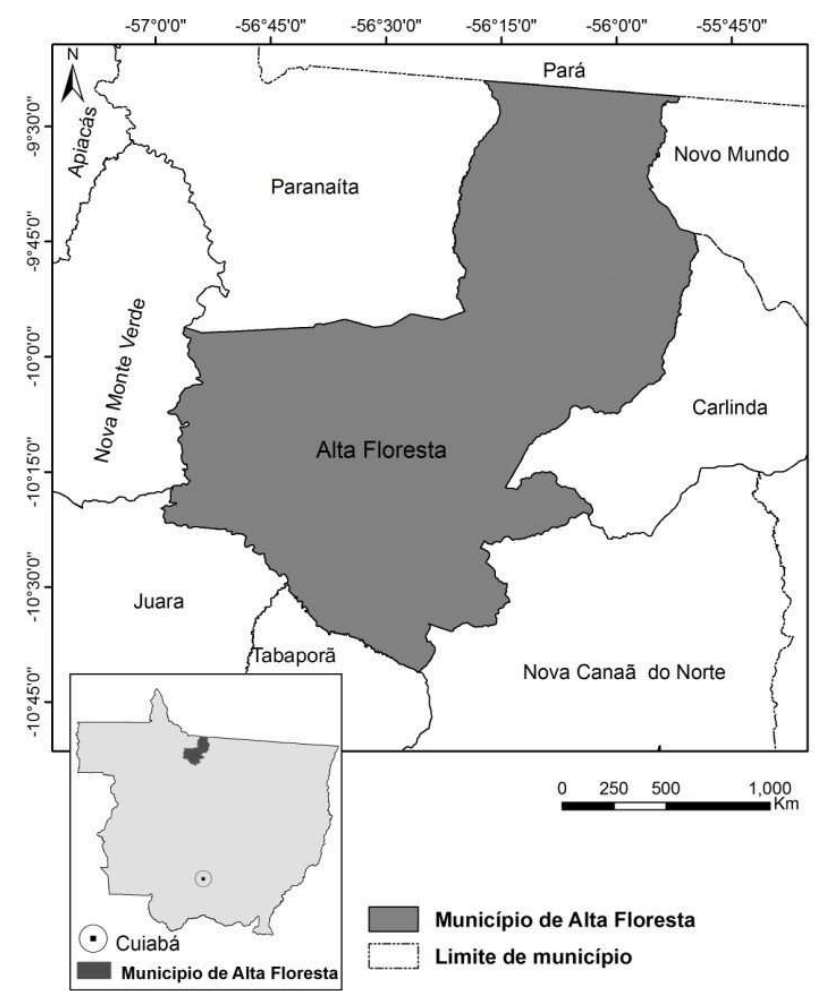

FIGURA 1. Localização da área de estudo, município de Alta Floresta - MT.

Fonte: CAIONI et al., (2014b).

O relevo faz parte do Planalto Apiacás-Sucurundi e da Depressão Interplanáltica Amazônica Meridional e apresenta várias serras em forma de cristas, que servem como divisores de água, posicionando-se entre 200 e $300 \mathrm{~m}$ de altitude (FARID, 1992). O clima, de acordo com a classificação de KÖPPEN (1948), é Equatorial, quente e chuvoso com temperaturas médias de 28 a $40^{\circ} \mathrm{C}$ no período de outubro a março e as baixas temperaturas não ultrapassam a $16^{\circ} \mathrm{C}$ no mês de julho. A vegetação encontra-se dentro do bioma Amazônia, sendo constituída por Florestas Ombrófilas, Florestas Estacionais e Formações Secundárias (BRASIL, 2007).

Para o presente estudo utilizou-se uma imagem digital do sensor HRV do satélite SPOT 5, com resolução espacial de 2,5 metros, do ano de 2007/MT do município de Alta Floresta georreferenciada, cedidas pela Secretaria Municipal de Meio Ambiente - SECMA/MT. Todo o geoprocessamento da imagem foi realizado pelo SIG ArcGIS 9.3.

Através de um shapefile "vazio", foram delimitadas amostras sobre a imagem, coletando informações sobre áreas homogêneas considerando as seguintes classes: área com cobertura vegetal (Mata); massas d'água (espelho d'água); área de influencia urbana; área de pastagem plantada e de solo exposto. 
Após as coletas e estruturação da tabela de atributos, utilizou-se a propriedade Create Signatures da ferramenta ArcToolBox para a geração das classes em formato matricial, onde este foi transformado em arquivo vetorial para edição mais detalhada e acabamento final. A análise de cada classe foi baseada na interpretação visual da imagem, considerando a textura, a cor e o padrão das feições (SERIGATTO, 2006).

Para análises mais pontuais, em APP, foi necessária a criação de buffers, delimitando deste modo 50 metros para áreas de nascentes e 30 metros para os cursos hídricos, conforme a lei estadual oㅜ 12.651/2012 (BRASIL, 2012). A partir do cruzamento do buffer com a imagem classificada, foi possível detectar o tamanho das áreas que se encontram irregulares, e os principais agentes que causam a supressão dos remanescentes florestais da microbacia. As quantificações das classes temáticas foram realizadas por meio da extensão Xtools disponível no módulo Arcmap do ArcGis.

\section{RESULTADOS E DISCUSSÃO}

O estudo permitiu verificar os diferentes níveis de uso e ocupação do solo da microbacia Lago da capivara (Figura 2), bem como a distribuição hidrográfica. Com uma área de 8.493,94 hectares, a microbacia apresentou uma hierarquia fluvial de até $3^{\text {a }}$ ordem, definidas a partir do grau de complexidade da drenagem. Conforme TONELLO et al. (2006), microbacias com maior hierarquia fluvial oferecem menores riscos de inundação devido a maior capacidade de escoamento hídrico.

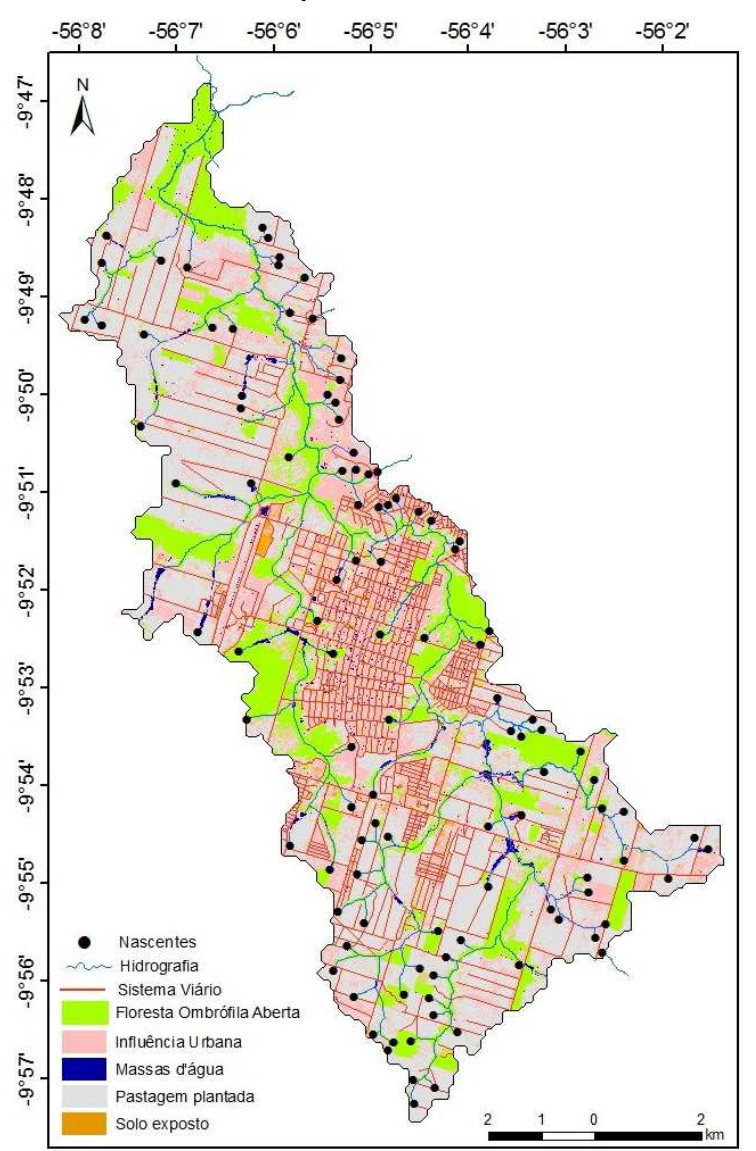

FIGURA 2. Uso do solo e cobertura vegetal da microbacia Lago da Capivara no ano de 2007.

Fonte: os autores. 
A classe Massas d'Água ocupou 0,81\% (68,80 ha) de toda a área. Uma das possíveis explicações para este moderado valor reside nas imagens serem obtidas durante a estação de seca. CAIONI et al. (2014b) ratificaram que a região onde está inserido o município de Alta Floresta exibe um definido período de estiagem.

Representando 41,61\% (3.534,33 ha) da área estudada, a classes Pastagem Plantada demostrou ser o principal uso antrópico do solo (Figura 2). Estes valores são reflexos do crescimento da pecuária extensiva dentro do município. Conforme NASCIMENTO et al. (2012), esta atividade atua como fonte de desmatamento em todo o país, devido a necessidade de conversão de extensas áreas em pastagem plantada.

Ocupando $25,41 \%(2.158,31$ ha) da microbacia, a classe Influência Urbana demostrou também ser um fator agravante e de difícil reversão, visto que parte das áreas que antes eram ocupadas pela vegetação nativa, hoje encontram-se em avançado estado de degradação, em decorrência da construção de casas, granjas, barracões e outras instalações. De acordo com CAIONI et al. (2014a), o processo de crescimento do perímetro urbano de Alta Floresta é contínuo, visto que ainda existem locais propícios a expansão dos bairros, sejam estes para fins residenciais ou comerciais.

Estando presente próximo a cursos hídricos, principalmente, a classe Floresta Ombrófila Aberta veio a ocupar apenas $15,58 \%$ (1.323,35 ha) de toda a área estudada. Este resultado corrobora com ARENAS et al. (2015), que constataram uma redução da cobertura vegetal na mancha urbana de Alta Floresta, entre os anos de 1984 a 1994. Evidenciou-se também maior intensidade da supressão da cobertura florestal próximo a estradas e rodovias, o que segundo FERREIRA et al. (2014) está possivelmente relacionado a facilidade de acesso a estes ambientes. Conforme FEARNSIDE (2003) esses resultados são preocupantes, visto que a retirada da floresta implica na perda de produtividade e biodiversidade, mudança no regime hidrológico e emissões de gases de efeito estufa durante a queima da floresta.

Estando possivelmente relacionada ao processo de degradação da pastagem, a classe Solo Exposto representou 0,95\% (80,69 ha) de toda a área. De acordo com NARDINI et al. (2015), o manejo inadequado aliado a falta de práticas conservacionistas leva a uma contínua degradação do solo. Portanto, evidenciou-se a necessidade de maiores investimentos em tecnologias que proporcionem melhorias nas qualidades físicas e químicas do solo.

Verificou-se para as Áreas de Preservação Permanente, situações que vão desde áreas florestadas até completamente desflorestadas (Figura 3). De acordo com OLIVEIRA et al. (2008), os agentes responsáveis pelo desmatamento partem muitas vezes de ações isoladas, que em conjunto provocam impactos maiores, alterando a configuração natural das microbacias.

Com 118 nascentes a microbacia Lago da Capivara totalizou 754,75 ha de APP. Destes, $23,38 \%(176,46$ ha) encontram-se ocupados pela classe Pastagem Plantada, $17,97 \%$ (135,63 ha) pela classe Influência Urbana e 0,37\% (2,79 ha) por Solo Exposto. Ao todo a microbacia apresentou 312,36 ha em descumprimento com a lei $n^{0}$ 12.651/2012. Segundo BLEICH et al. (2013), as consequências da supressão das áreas de mata ciliar não restringem somente aos recursos hídricos, mas também a diversidade biológica. Isto ocorre porque a redução das áreas de refúgio de fauna ocasiona alterações nas interações ecológicas e consequentemente a extinção de diversas espécies. 


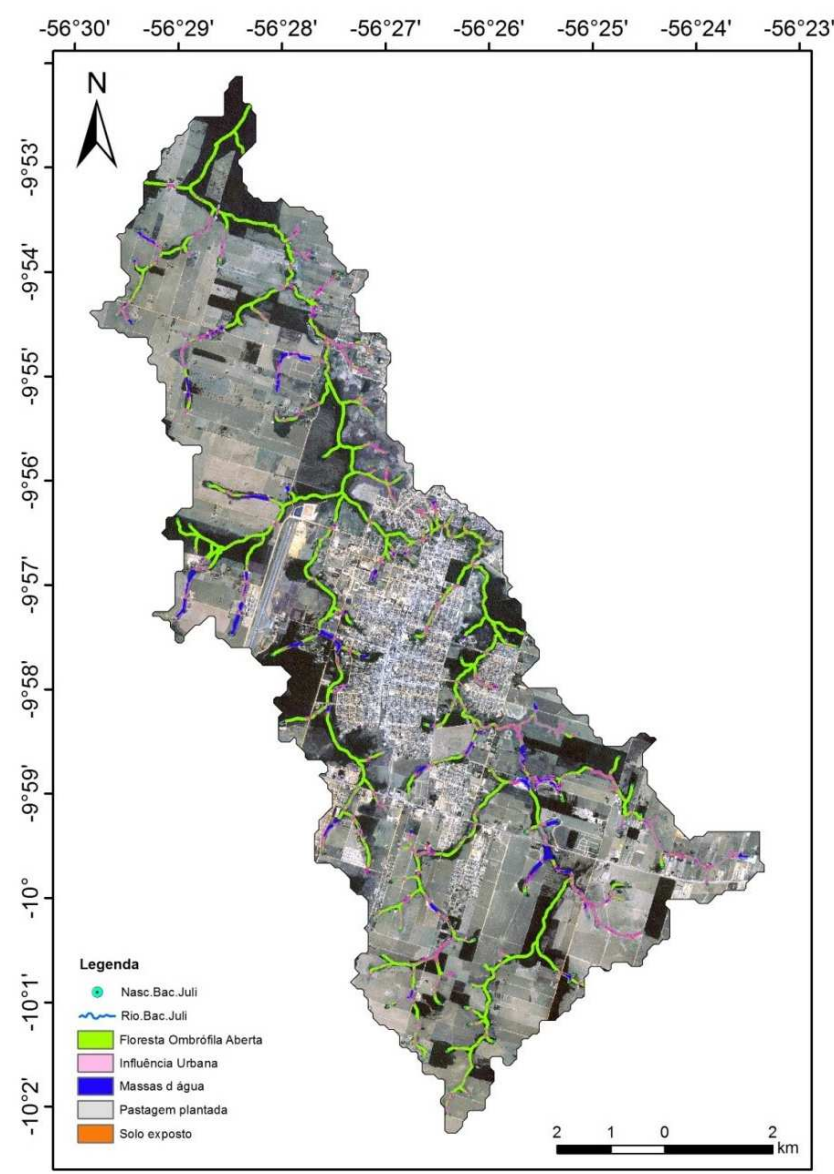

FIGURA 3. Mapa de uso da terra nas APPs da Fonte: os autores. microbacia Lago da Capivara.

A classe pastagem plantada configurou-se como a de maior uso antrópico dentro das APP's. De acordo com NUNES et al. (2015), no município de Alta Floresta a remoção da vegetação ripária para a formação de pastagens foi realizada de forma desordenada e com a inexistência de qualquer tipo de precaução.

A classe Floresta Ombrófila Aberta apresentou-se como a classe de maior representatividade dentro das APPs. Entretanto, esse valor é muito baixo mediante a sua importância para proteção desses ambientes (LAURENTINO \& SOUZA, 2013). De acordo com FREITAS et al. (2013), as matas ciliares exercem inúmeras funções, como a interceptação do impacto direto das águas meteóricas, a redução e retardamento do escoamento superficial e o aumento da infiltração de água no solo, que dificulta o desenvolvimento de processos erosivos.

As evidencias de presença de bovinos dentro das matas ciliares também foi algo preocupante, visto que o pisoteio dos animais ocasiona tanto a compactação do solo quanto o retardamento do desenvolvimento das espécies arbóreas (FELIPE et al., 2015). Para tanto, sugere-se não somente a criação de cercas ao redor da mata ciliar, mas também a implantação de novas espécies nativas por meio de sementes e mudas, visto que esse procedimento permite potencializar a recuperação dessas áreas. 


\section{CONCLUSÃO}

Constatou-se que o uso das ferramentas de geoprocessamento no diagnóstico dos principais usos do solo da microbacia Lago da Capivara mostrou-se eficiente, sobretudo na análise de supressão das matas ciliares.

As classes Pastagem Plantada e Influência Urbana demonstraram ser as principais ocupações do solo dentro de toda a microbacia. Referente às Áreas de Preservação Permanente, estas apresentaram avançado estado de perda de matas ciliares, sendo a classe Pastagem Plantada o principal uso antrópico.

De modo geral, é possível afirmar que existe uma urgente necessidade de tomada de ações mitigadoras de conservação, uma vez que a perda da cobertura florestal em áreas de APP pode pôr em risco a perpetuação da disponibilidade hídrica da microbacia.

\section{REFERÊNCIAS}

ARENAS, M. D.; NEVES, S. M. A.; ROSSI, A. A. B.; COCHEV, J. S.; SILVA, I. V. Cobertura vegetal de Alta Floresta, Amazônia Meridional Matogrossense. Revista ESPACIOS, v. $36, \quad$ n. 20 , p. 15, 2015. Disponível em: < http://www.revistaespacios.com/a15v36n20/15362015.html>.

BLEICH, M. E.; SILVA, C. J. Caracterização dos fragmentos florestais amazônicos remanescentes na microbacia hidrográfica do rio Taxidermista I em Alta Floresta, MT. Biotemas, v. 26, n. 4, p. 45-51, 2013. Disponível em: < https://periodicos.ufsc.br/index.php/biotemas/article/view/2175-7925.2013v26n4p45 >. doi: http://dx.doi.org/10.5007/2175-7925.2013v26n4p45.

BRASIL. Lei $\mathbf{n}^{\circ} \mathbf{1 2 . 6 0 8}$, de 10 de abril de 2012. Institui a Política Nacional de Proteção e Defesa Civil - PNPDEC. Presidência da República. Casa Civil. Subchefia;para;Assuntos;Jurídicos.;Disponível;em<http://www.planalto.gov.br/ccivil_ 03/_Ato2011-2014/2012/Lei/L12608.htm >. Acesso em 15 nov de 2016. .

\section{BRASIL - MINISTÉRIO DO MEIO AMBIENTE. Mapas de Cobertura Vegetal dos Biomas $\quad$ Brasileiros. $2007 . \quad$ Disponível.em:<} http://www.mma.gov.br/estruturas/sbf_chm_rbbio/_arquivos/mapas_cobertura_veget al.pdf $>$. Acesso em 25 de nov de 2016.

CAIONI, C.; CAIONI, S.; PARENTE, T. L.; SILVA, A. C. S.; CLAUDINO, W. V. Dinâmica da temperatura superficial no perímetro urbano de Alta Floresta/MT. Enciclopédia Biosfera, v. 10, n. 18, p. 3853-3863, 2014a. Disponível em:< http://www.conhecer.org.br/enciclop/2014a/MULTIDISCIPLINAR/dinamica.pdf >.

CAIONI, C.; CAIONI, S.; SILVA, A. C. S.; PARENTE, T. L.; ARAUJO, O. S. Análise da distribuição pluviométrica e de ocorrência do fenômeno climático ENOS no município de Alta Floresta/MT. Enciclopédia Biosfera, v. 10, n. 19, p. 2656-2666, 2014b..Disponível.em:

http://www.conhecer.org.br/enciclop/2014b/MULTIDISCIPLINAR/Analise\%20da\%20d istribuicao.pdf $>$. 
FARID, L. H. Diagnóstico preliminar dos impactos ambientais gerados por garimpos de ouro em Alta Floresta - MT: um estudo de caso. Rio de Janeiro: CETEM/ CNPq, 1992. 190p.

FEARNSIDE, P. M. A Floresta Amazônica nas Mudanças Globais. Manaus: Editora do Instituto Nacional de Pesquisas da Amazônia, 2003. 134 p.

FELIPE, A. C.; CAMPOS, S.; GARCIA, Y. M.; DE CAMPOS, M.; POLLO, R. A. Caracterização das áreas de conflito de uso da terra em APP na Microbacia Ribeirão do Veado, Piratininga (SP) por meio de geotecnologias. Energia na agricultura, v. 30 , n. 4, p. 357-362, 2015. Disponível em:< http://revistas.fca.unesp.br/index.php/energia/article/viewFile/1942/pdf_58>. doi: http://dx.doi.org/10.17224/EnergAgric.2015v30n4p357-362.

FERREIRA, R. A. S.; SANTOS, S. K. F.; SILVA, E. P.; SILVA, A. C. S. E.; CAIONI, C. Estruturação de dados geoambientais do Assentamento Rural Jacaminho, Município de Alta Floresta - Mt. Enciclopédia Biosfera, v. 10, n. 18, p. 1637, 2014. Disponível em:

http://www.conhecer.org.br/enciclop/2014a/AGRARIAS/estruturacao.pdf>.

FREITAS, E. P. Análise Integrada do Mapa de Uso e Ocupação das Terras da Sub bacia do Rio Jundiaí-Mirim para fins de Gestão Ambiental. 2012. $120 f$. Dissertação (Mestrado em Agricultura Tropical e Subtropical) Curso de Pós Graduação em Agricultura Tropical e Subtropical. Campinas, Instituto Agronômico.

FREITAS, E. P.; MORAES, J. F. L.; PECHE FILHO, A.; STORINO, M. Indicadores ambientais para áreas de preservação permanente. Revista Brasileira de Engenharia Agrícola e Ambiental, v. 17, n. 4, p. 443-449, 2013. Disponível em: < http://www.agriambi.com.br/revista/v17n04/v17n04a13.pdf>.

doi: http://dx.doi.org/10.1590/S1415-43662013000400013.

IBGE - INSTITUTO BRASILEIRO DE GEOGRAFIA E ESTATÍSTICA Confederação.Nacional.de.municípios..Disponível.em: < http://cidades.ibge.gov.br/xtras/perfil.php?codmun=510025>. Acesso em 25 de nov de 2016.

KÖPPEN, W, Climatologia con un estudio de los climas de la Tierra, México, Fondo de Cultura Econômica, 1948.

LACORTE, I. M.; ALMEIDA, M. R. R. Impactos ambientais em Áreas de Preservação Permanente de centros urbanos: o caso da bacia do Córrego Liso em Uberlândia. Enciclopédia Biosfera, v. 11, n. 22, p. 1464-1475,.2015..Disponível.em:.< http://www.conhecer.org.br/enciclop/2015c/agrarias/impactos\%20ambientais.pdf>.

LAURENTINO, I. C.; SOUZA, S, C. Uma análise do plano de recuperação de área degradada com vegetação de mangue no Rio Apodi Mossoró do projeto margem viva. Revista Holos, v. 3, p. 161-170, 2013. Disponível em: < http://www2.ifrn.edu.br/ojs/index.php/HOLOS/article/view/1321/690>. doi: http://dx.doi.org/10.15628/holos.2013.1321. 
LONGLEY, P. A.; MAGUIRE, D. J.; GOODCHILD, M. F., RHIND, D. W. Sistemas e Ciência da Informação Geográfica. 3. Ed. Porto Alegre: Bookman. 2013.

MARTIN, N.B. Manejo de microbacias: o caso do Paraná Rural. in LOPES, et al Gestão ambiental no Brasil: experiência e sucesso. FGV, ed.4, 2000.

NARDINI, R. C.; CAMPOS, S.; RIBEIRO, F. L.; GOMES, L. N.; FELIPE, A. C.; CAMPOS, M. D. Avaliação das áreas de conflito de uso em APP na microbacia do ribeirão Morro Grande. Caminhos de Geografia, v. 16, n. 55, p. 104-113, 2015. Disponível

em:< http://www.seer.ufu.br/index.php/caminhosdegeografia/article/viewFile/26353/17258>

NASCIMENTO, F. M.; BARROS, Z. X.; BARROS, B. S. X.; CAMPOS, S.; RODRIGUES, J. G. L. Uso de SIG e fotografias aéreas na determinação de conflitos na rede de drenagem na Bacia Experimental do Rio Pardo. Irriga, v. 17, n. 3, p. 346352, $2012 . \quad$ Disponível em:< http://irriga.fca.unesp.br/index.php/irriga/article/viewFile/343/295>. doi: http://dx.doi.org/10.15809/irriga.2012v17n3p346.

NUNES, E. J. D. S.; SILVA, E. P. D.; SOUZA, E. D.; ROCHA FILHO, J. A. D.; SILVA, D. S. N. D. Geotecnologias no diagnóstico de conflitos de uso do solo de uma microbacia do município de Alta Floresta-MT. Ciência Florestal, v. 25, n. 3, p. 689697, 2015. Disponível em: < http://www.scielo.br/pdf/cflo/v25n3/1980-5098-cflo-2503-00689.pdf>. doi: http://dx.doi.org/10.5902/1980509819619.

OLIVEIRA, E. M. D.; SANTOS, W. M. B.; MORAIS, J. L. D.; BASSETTI, F. D. J.; BERGAMASCO, R. Percepção ambiental e sensibilização de alunos de colégio estadual sobre a preservação de nascente. Revista Eletrônica do Mestrado em Educação Ambiental, v. 30, n. 1, p. 23-37, 2013. Disponível em:< https://www.seer.furg.br/remea/article/view/3532/2216>.

OLIVEIRA, P. C. A; RODRIGUES, G. S. S. C; RODRIGUES, S. C. Fragilidade ambiental e uso do solo da Bacia Hidrológica do Córrego Pindaíba, Uberlândia, MG, Brasil. Revista Ambiente \& Agua, v. 3, n. 1, p. 54-67, 2008. Disponível em:< http://www.ambi-agua.net/seer/index.php/ambi-agua/article/view/70/193>. doi: http://dx.doi.org/10.4136/ambi-agua.42.

PNUD. Programa das Nações Unidas para o Desenvolvimento. Atlas de Desenvolvimento Humano. Índice de Desenvolvimento Humano (IDH) dos municípios brasileiros (Alta Floresta). Disponível em: < http://www.atlasbrasil.org.br/2013/pt/perfil_m/alta-floresta_mt>. Acesso em 26 jan de 2016.

SERIGATTO, E. M. Delimitação automática das áreas de preservação permanente e identificação dos conflitos de uso da terra na bacia hidrográfica do Rio Sepotuba - MT. 2006. 203f. Tese (Doutorado em Engenharia Florestal)Programa de Pós- Graduação em Ciência Florestal. Viçosa, Universidade Federal de Viçosa.

Disponível em: 
http://www.locus.ufv.br/bitstream/handle/123456789/525/texto\%20completo.pdf?seq uence $=1>$.

SILVA, R. V.; SOUZA, C. A. Ocupação e degradação na margem do Rio Paraguai em Cáceres, Mato Grosso. Revista Brasileira de Gestão e Desenvolvimento Regional, v. $8, \quad$ n. 1 , p. 125-152, 2012. Disponível em: < http://rbgdr.net/revista/index.php/rbgdr/article/viewFile/587/274>.

TONELLO, K. C.; DIAS, H. C. T.; SOUZA, A. L.; RIBEIRO, C. A. A. S.; LEITE, F. P. Morfometria da bacia hidrográfica da Cachoeira das Pombas, Guanhães-MG. Revista Árvore, v. 30, n. 5, p. 849-857, 2006. Disponível em: <http://www.scielo.br/pdf/rarv/v30n5/a19v30n5.pdf>. doi: http://dx.doi.org/10.1590/S0100-67622006000500019. 